BenthaM OPEN The Open Nanomedicine Tumen

RESEARCH ARTICLE

\title{
Formulation and In-Vitro Evaluation of Solid Lipid Nanoparticles Containing Levosulpiride
}

\author{
Sukhwinder Singh, Sukhmeet Singh Kamal, Amit Sharma, Daljit Kaur, Manoj Kumar Katual and \\ Rajesh Kumar*
}

Rayat-Bahra Institute of Pharmacy - Pharmaceutics Hoshiarpur, Punjab, India

Received: June 24, 2017

Revised: September 10, 2017

Accepted: September 25, 2017

\section{Abstract:}

Objectives:

The present study aims on preparing Levosulpiride loaded solid lipid nanoparticles (SLNs) to reduce the dose, frequency of dosing, reduce side effects and to increase the bioavailable fraction of drug ( $<30 \%$ orally in general).

\section{Methods:}

Levosulpiride was characterized by preformulation studies like physical appearance, melting point, assay, calibration curve, FTIR analysis and DSC analysis. The calibration curve of the drug was prepared in $\mathrm{pH} 6.8$ phosphate buffer. Two lipids (Stearic acid and Palmitic acid) were used as lipid phase to prepare SLNs. Factorial design (23) was applied to formulate 16 formulations ( 8 for each lipid i.e. SF1-SF8 and PF1-PF8). Levosulpiride SLNs were prepared by solvent evaporation method followed by homogenization.

Results:

The optimized formulations were characterized by particle size analysis, zeta potential analysis, in vitro drug release and drug release kinetics. Drug-excipient interaction in optimized formulation was characterized by FTIR, DSC and TEM analysis.

\section{Conclusion:}

On the basis of evaluation parameters, the formulation SF1 (containing Stearic acid) and PF1 (containing Palimitic acid) found to be better formulations amongst their groups with a controlled drug release after a period of $24 \mathrm{hrs}$.

Keywords: Levosulpiride, Homogenization, Lipid, Nanoparticle, Assay, Calibration curve.

\section{INTRODUCTION}

In the recent years, with the advent of Nanomedicine, engineered tunable devices with the size in the order of billions of meters have been proposed as an intriguing tool potentially able to solve the unmet problem of enhancing drug transport across the BBB [1]. Amongst different devices, nanoparticles (NPs) technology is rapidly advancing. Nanotechnology refers to structures with a size range of $1-100 \mathrm{~nm}$ in at least one dimension [2]. Nanotechnology is the application of science and technology to control matter at the molecular level. At the nanoscale level, the properties of matter are significantly different from their macroscopic bulk properties [3]. Nanotechnology also refers to the ability for designing, characterization, production and application of structures, devices and systems by controlling shape and size at the nanometer scale. One area where nanotechnology has the potential to make a significant impact is drug [4]. This impact has already been felt with the translation of several nanoscale drug delivery systems into the clinic, although the full potential of these systems is only starting to be explored. Nanoscale drug delivery vehicles have shown

\footnotetext{
* Address correspondence to this author at the Rayat-Bahra Institute of Pharmacy - Pharmaceutics Hoshiarpur, Punjab, India; Tel:
} +91-9855976499; Fax: 01882-275500; E-mail: rajksach09@gmail.com 
the ability to encapsulate a variety of therapeutic agents such as small molecules (hydrophilic and/or hydrophobic), peptides, protein-based drugs, and nucleic acids [5]. Because of their unique size range, nanoparticles exhibit "enhanced permeability and retention effect" (EPR) which confirm their potential in specific targeting so as to maximize the therapeutic effects and minimize the undesirable effects [6].

Amongst various nanoparticles, solid lipid nanoparticles (SLNs), introduced in 1991 represent an alternative carrier system to traditional colloidal carriers, such as emulsions, liposomes and polymeric nanoparticles [7]. SLNs are small sized lipid nanoparticles composed of biocompatible and biodegradable solid lipids. Their matrix is composed of physiological lipids which reduce the danger of acute and chronic toxicity [8]. Irrespective of their small size (10-1000nm), they offer a high drug loading capacity, larger surface area and thus enhanced bioavailability. These characteristics make SLNs an interesting drug delivery system [9].

Levosulpiride (substituted benzamide: a levo-isomer of Sulpiride) was used as a model drug in the present study. Levosulpiride is chemically N-[[(2S)-1- Ethylpyrrolidin-2-yl] methyl]-2-methoxy-5- sulfamoylbenzamide with molecular formula $\mathrm{C}_{15} \mathrm{H}_{23} \mathrm{~N}_{3} \mathrm{O}_{4} \mathrm{~S}$ and molecular weight 341.43 as shown in Fig. (1) [10].

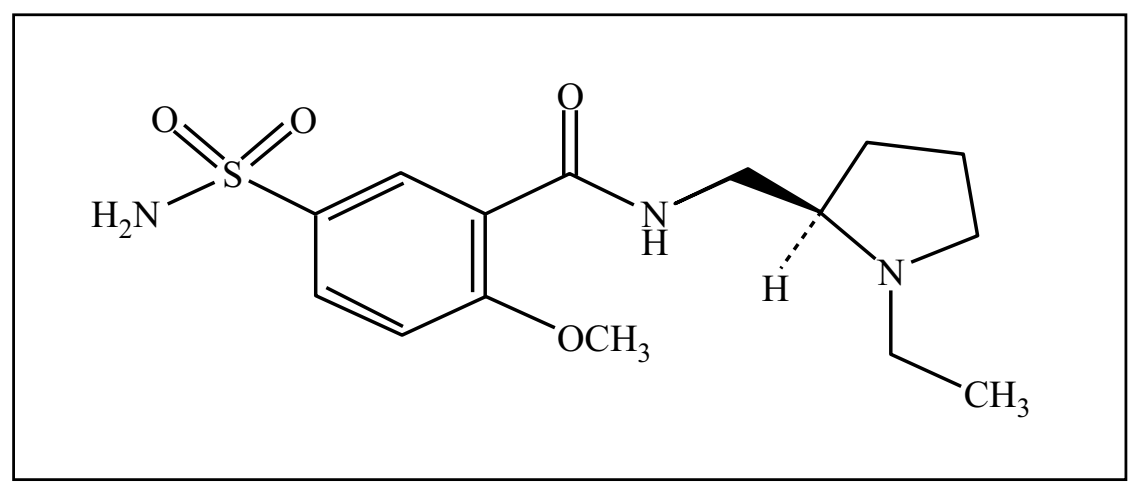

Fig. (1). Chemical structure of levosulpiride.

Levosulpiride blocks the presynaptic dopaminergic D2 receptors. Like its parent compound, Levosulpiride shows antagonism at D3 and D2 receptors present presynaptically as well as postsynaptically. The preferential binding of the presynaptic dopamine receptors decreases the synthesis and release of dopamine at low doses whereas it causes postsynaptic D2 receptor antagonism at a higher dose [11]. It is an Atypical Neuroleptic (Anti-Psychotic) and also has proven prokinetic effect making it useful in the treatment of various GI disorders. It is also reported to interact with serotonergic receptors. It has moderate to partial 5-HT4 receptor agonist property and very weak 5-HT3 antagonism [12] making it a useful antiemetic. Levosulpiride does not cause much of extrapyramidal side effects as observed with metoclopramide. Extrapyramidal or sleep disturbances may be seen at very high doses. It is a useful drug in gastro esophageal reflux disease, diabetic gastroparesis, nausea and vomiting, chemotherapy-induced emesis and irritable bowel syndrome. It can be administered parenterally as well as orally and the most common adverse effects include drowsiness/ sedation and endocrine effects like amenorrhea, gynecomastia, galactorrea and decrease libido [13]. Bioavailability of Levosulpiride is $<30 \%$ indicating a first pass effect. $T_{\max }$ is 3 hours. Half life ( $\left.\mathrm{t}_{1 / 2}\right)$ of the drug is 6 hours and it takes 3 hours (i.e. $\mathrm{t}_{\max }$ ) to reach to $\mathrm{c}_{\max }$. Plasma protein binding is $>40 \%$. The volume of distribution is 0.85 $\mathrm{L} / \mathrm{kg}$ [7]. Metabolism is reported hepatic, but very low. Renal Excretion accounts for unchanged $25 \%$. The drug is substantially excreted in the feces due to poor absorption. The lack of hepatic metabolism makes metabolic interactions with cytochrome P-450 related substrates very unlikely [14].

Currently available dosage forms of Levosulpiride are administered through oral route in the form of extended release and immediate release tablets (e.g. Pirivo, Perfame, Levogut). The major drawback with available marketed formulations is the availability of drug in a very limited amount in the target tissue. The bioavailable fraction of the drug reaching CNS of Schizophrenia affected patient from currently available dosage form is not that optimum for producing the desired amount of therapeutic effect. The present study tries to enlighten the prior art related to Schizophrenia treatment and to prepare a Levosulpiride loaded nanoparticles that may overcome the problem of bioavailability and cross the blood brain barrier with sustained effect thereby decreasing the dosing frequency and increasing the patient compliance. 
So the aim of the present study was to prepare Levosulpiride loaded SLNs by solvent evaporation followed by homogenization technique and to evaluate the physicochemical properties of obtained Levosulpiride loaded SLNs, such as mean particle size, zeta potential, drug entrapment efficiency, in vitro drug release and drug release kinetics evaluation. The effects of composition of lipid materials and surfactant mixture on particle size, zeta potential, drug entrapment efficiency, and in vitro drug release behavior were investigated in detail. FTIR and DSC analyses were performed to investigate the status of the lipid and the drug. Shape and surface morphology of the formulated nanoparticles was determined by TEM.

\section{MATERIALS AND METHOD}

\subsection{Chemicals}

Levosulpiride was received as a gift sample from Shagun Pharmaceuticals Pvt. Ltd; Maharashtra (India). Stearic acid and Palmitic acid were generously supplied by CDH (P) Ltd., New Delhi. Tween 80 was purchased from Qualikems Fine Chemicals Pvt. Ltd. Span 60 was purchased from Loba Chemie, Mumbai, Ethanol was purchased from Changshu Yangyuan Chemicals, China and dialysis membrane-70 (MW cutoff, 8-12 kDa) from Hi-Media (Mumbai, India). The other chemicals were of analytical reagent grade and were used as received.

\subsection{Preformulation Studies}

\subsubsection{Melting Point}

Melting point of the drug was determined by taking a small amount of drug in a capillary tube closed at one end and was placed in digital melting point apparatus and the temperature at which the drug melted was noted down.

\subsubsection{Assay}

Assay of the drug was performed by UV spectrophotometric method. Levosulpiride (10 $\mathrm{mg}$ ) was dissolved in few $\mathrm{ml}$ of phosphate buffer ( $\mathrm{pH}$ 6.8) and volume was made up to $100 \mathrm{ml}$ in the volumetric flask using phosphate buffer (pH 6.8). From this stock solution $1 \mathrm{ml}$ solution was withdrawn and diluted up to $10 \mathrm{ml}$ in volumetric flask $(10 \mu \mathrm{g} / \mathrm{ml})$. The absorbance of the solution was measured at scanned wavelength (291.2 nm) using UV spectrophotometer [15].

\subsubsection{Calibration Curve}

Accurately weighed $10 \mathrm{mg}$ of Levosulpiride was transferred into a $10 \mathrm{ml}$ volumetric flask. A few $\mathrm{mL}$ of $\mathrm{pH} 6.8$ phosphate buffer was added to it and shook well. The solution was sonicated for 1 minute in bath sonicator and diluted up to the mark with pH 6.8 phosphate buffer to have a stock solution. From this stock solution, further dilutions were made.

\subsection{Preparation of Levosulpiride Loaded Solid Lipid Nanoparticles}

Levosulpiride, stearic acid / palmitic acid, and span 60 were dissolved in ethanol to prepare the lipid phase. The aqueous phase was prepared by mixing tween 80 in distilled water with magnetic stirrer. Ethanol from lipid phase was evaporated and when a wet mass was left, then this drug-embedded lipid layer was slowly poured in aqueous solution homogenizing at $10,000 \mathrm{rpm}$ for 10 minutes $[16,17]$. A full factorial design $\left(2^{3}\right)$ was employed for formulation batches (i.e. 8 formulations for each lipid) in which 3 factors namely lipid (stearic acid and palmitic acid), span 60 and tween 80 were tested at 2 levels of their concentration i.e. low and high. The effect of different levels of factors was evaluated at the particle size of resultant formulation (i.e. response). The composition of stearic acid and palmitic acid formulation batches are given in Tables 1 and $\mathbf{2}$ respectively.

Table 1. Composition of Stearic acid formulations.

\begin{tabular}{|c|c|c|c|c|c|c|c|c|}
\hline \multirow{2}{*}{ Ingredients } & \multicolumn{8}{|c|}{ Formulations } \\
\hline & SF1 & SF2 & SF3 & SF4 & SF5 & SF6 & SF7 & SF8 \\
\hline Levosulpiride (mg) & 10 & 10 & 10 & 10 & 10 & 10 & 10 & 10 \\
\hline Stearic Acid (mg) & 100 & 200 & 100 & 200 & 100 & 200 & 100 & 200 \\
\hline Span 60 (mg) & 50 & 50 & 100 & 100 & 50 & 50 & 100 & 100 \\
\hline Tween $80(\mathrm{~mL})$ & 0.50 & 0.50 & 0.50 & 0.50 & 0.75 & 0.75 & 0.75 & 0.75 \\
\hline Ethanol (mL) & q.s & q.s & q.s & q.s & q.s & q.s & q.s & q.s \\
\hline
\end{tabular}


(Table $\square$ ) contd.....

\begin{tabular}{|c|c|c|c|c|c|c|c|c|}
\hline \multirow{2}{*}{ Ingredients } & \multicolumn{8}{|c|}{ Formulations } \\
\hline & SF1 & SF2 & SF3 & SF4 & SF5 & SF6 & SF7 & SF8 \\
\hline Dist. Water (mL) & 25 & 25 & 25 & 25 & 25 & 25 & 25 & 25 \\
\hline
\end{tabular}

\subsection{Characterization of Formulated SLNs}

\subsubsection{Measurement of Particle Size and Zeta Potential}

The average particle size and zeta potential of the Levosulpiride loaded SLN formulations were estimated using Beckman Coulter Zeta sizer. The number of particles present in the size range, the average particle size and zeta potential were determined.

Table 2. Composition of Palmitic acid formulations.

\begin{tabular}{|l|c|c|c|c|c|c|c|c|}
\hline \multirow{2}{*}{ Ingredients } & \multicolumn{9}{|c|}{ Formulations } & PF7 & PF8 \\
\cline { 2 - 10 } & PF1 & PF2 & PF3 & PF4 & PF5 & PF6 & PF \\
\hline Levosulpiride $(\mathrm{mg})$ & 10 & 10 & 10 & 10 & 10 & 10 & 10 & 10 \\
\hline Palmitic Acid (mg) & $\mathbf{1 0 0}$ & $\mathbf{2 0 0}$ & $\mathbf{1 0 0}$ & $\mathbf{2 0 0}$ & $\mathbf{1 0 0}$ & $\mathbf{2 0 0}$ & $\mathbf{1 0 0}$ & $\mathbf{2 0 0}$ \\
\hline Span $60(\mathrm{mg})$ & 50 & 50 & 100 & 100 & 50 & 50 & 100 & 100 \\
\hline Tween $80(\mathrm{~mL})$ & 0.50 & 0.50 & 0.50 & 0.50 & 0.75 & 0.75 & 0.75 & 0.75 \\
\hline Ethanol $(\mathrm{mL})$ & q.s & q.s & q.s & q.s & q.s & q.s & q.s & q.s \\
\hline Distilled Water $(\mathrm{mL})$ & 25 & 25 & 25 & 25 & 25 & 25 & 25 & 25 \\
\hline
\end{tabular}

\subsubsection{Drug Entrapment Efficiency}

The percentage of entrapped Levosulpiride was determined spectrophotometrically at $291.2 \mathrm{~nm}$. After centrifugation of the aqueous suspension, the amount of the free drug was detected in the supernatant and the amount of entrapped drug was determined as the result of the initial drug minus the free drug [18]. The entrapment efficiency can be calculated using the following formula:

$$
\% \mathrm{EE}=\{(\text { Total drug content }- \text { Free drug content }) / \text { Total drug content }\} \text { X } 100
$$

\subsubsection{In Vitro Drug Release Study}

Drug release study was carried out in phosphate buffer $\mathrm{pH} 6.8$ for 24 hours. The buffer was prepared using the method quoted before. In vitro drug release study was carried out by incubating $10 \mathrm{~mL}$ of formulation (placed in a small cylinder fitted with $8-12 \mathrm{kDa}$ membrane at the bottom) in $50 \mathrm{~mL} \mathrm{pH} 6.8$ phosphate buffer maintained at $37^{\circ} \mathrm{C}$ with continuous stirring with a magnetic stirrer [19]. The samples $(2 \mathrm{~mL}$ each) were withdrawn periodically and the equal volume of medium was replaced after each withdrawal. The samples collected were then analyzed for the amount of drug released by measuring absorbance at $291.2 \mathrm{~nm}$ using a UV-Visible double beam spectrophotometer [20].

\subsubsection{Drug Release Kinetics}

The cumulative amounts of Levosulpiride release from the polymeric nanoparticles at different intervals were fitted with zero-order kinetic model, first order kinetic model, Higuchi model and Korsmeyer- Peppas model to characterize the mechanism of drug release $[21,22]$.

\subsubsection{Fourier Transform Infra-Red Spectroscopy (FTIR)}

The FTIR spectra of the native drug Levosulpiride as well as the selected formulations were recorded to study the functional groups present in the individual samples. The $\mathrm{KBr}$ sample discs were prepared by individually compressing the drug and formulation samples. The infrared spectra were recorded in the wave number range of $4000-400 \mathrm{~cm}^{-1} \mathrm{using}$ FTIR spectrophotometer and the characteristic bands were observed.

\subsubsection{Differential Scanning Calorimetry}

The thermal behavior of Levosulpiride and formulations were investigated using a Universal V4.5A TA DSC (Universal Instuments, USA). Accurately weighed samples $(3.13 \mathrm{mg}$ ) were placed in standard aluminium pans and covered with a pierced lid. Dry nitrogen was used as the purge gas, at a flow rate of $50 \mathrm{~mL} / \mathrm{min}$. The thermograms were obtained by heating the samples at a rate of $10^{\circ} \mathrm{C} / \mathrm{min}$ within a temperature range of $30^{\circ} \mathrm{C}$ temperature to $300^{\circ} \mathrm{C}$. The melting point was observed. 


\subsubsection{Transmission Electron Microscopy (TEM)}

Morphology of the prepared nanoparticless was observed by Transmission Electron Microscopy (TEM) with magnification of 2,70,000X. Drug loaded SLNs were diluted with distilled water and sonicated. Few drops of the diluted nanoparticles were placed on Copper $(\mathrm{Cu})$ grid; this $\mathrm{Cu}$ grid was placed in sample holder and placed into the machine to capture the images of particles.

\section{RESULTS AND DISCUSSION}

\subsection{Preformulation Studies}

Levosulpiride is a white to cream colored crystalline powder in appearance with a reported melting point of $177-181^{\circ} \mathrm{C}$.

\subsubsection{Melting Point}

The value of observed melting point range is given in the Table $\mathbf{3}$ below along with the reported melting point range [23]. Practically observed value of melting point was in accordance with the reported value.

Table 3. Observed melting point of levosulpiride.

\begin{tabular}{|c|c|c|}
\hline Parameter & Reference value & Experimental value \\
\hline Melting point & $177-181^{\circ} \mathrm{C}$ & $180 \pm 0.6^{\circ} \mathrm{C}$ \\
\hline
\end{tabular}

*Mean \pm S.D.

\subsubsection{Assay}

Assay of the drug was performed by UV spectrophotometric method at a scanned wavelength of $291.2 \mathrm{~nm}$. The drug content was found to be in the range of $98.90-99.82 \%$, which is within acceptable limits [15].

\subsubsection{Calibration Curve}

Absorbance of each solution was recorded at $291.2 \mathrm{~nm}$ against $\mathrm{pH} 6.8$ phosphate buffer as blank. The calibration curve of absorbance vs. concentration was plotted and correlation co-efficient and regression equation for Levosulpiride were determined. The drug was found to show linearity in a concentration range of 10 to $100 \mu \mathrm{g} / \mathrm{mL}$ [23 - 24]. The calibration curve is shown in Fig. (2).

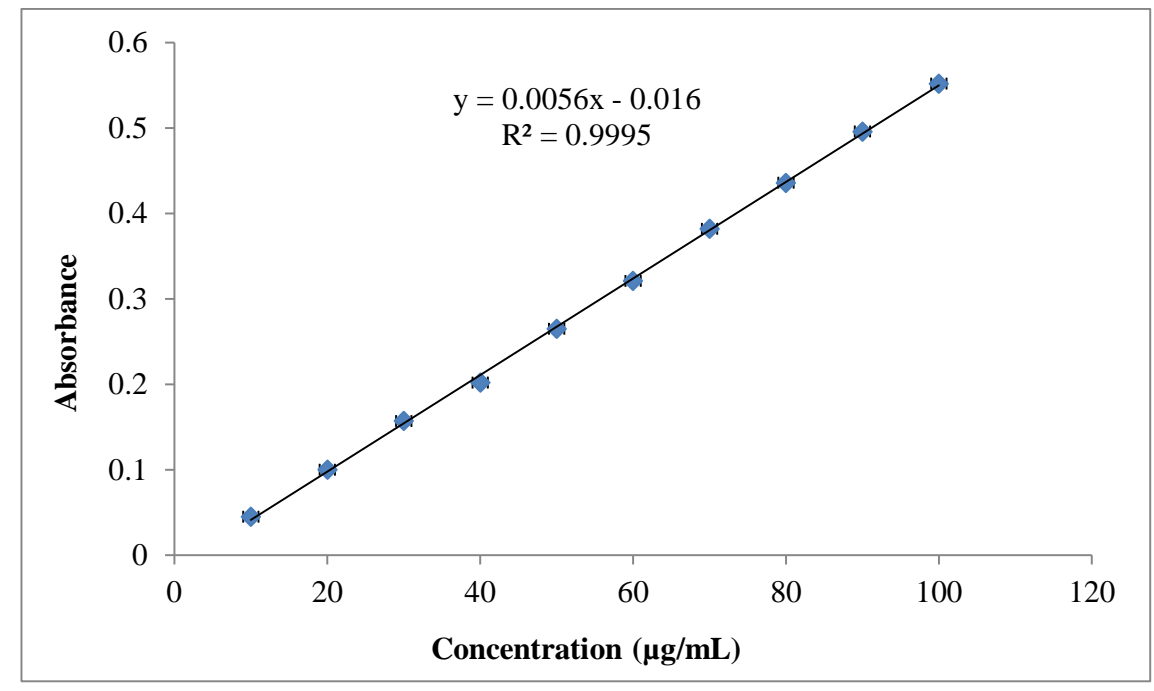

Fig. (2). Calibration curve of drug in $\mathrm{pH} 6.8$ phosphate buffer. The error bars indicate the standard deviation of three tests.

\subsection{Measurement of Particle Size and Zeta Potential}

Since our aim was to achieve SLNs with particle size small enough for brain applications, one of the first tasks was to identify the experimental parameters that govern the particle size. The formulations were characterized for particle size analysis. A total of 16 formulations (SF1-SF8 \& PF1-PF8) were prepared employing $2^{3}$ full factorial design, 
amongst which only six formulations (three of each lipid) i.e. SF1, SF2, SF6 and PF1, PF2, PF6 were found to be in required nanometer $(\mathrm{nm})$ size range and other formulations were found to possess particle size beyond $250 \mathrm{~nm}$. A combination of both tween 80 (aqueous surfactant) and span 60 (lipid surfactant) was found to be optimum in selected formulations owing to their smaller particle size as well as lower polydispersity index (indicative of stability of formulation as well as homogeneity of dispersion) than other formulations (Tables $\mathbf{4}$ and $\mathbf{5}$ ). This was probably due to more solubilization of drug in lipid and better stabilization of the formulations. These results were further confirmed by zeta potential studies (Table 6). The formulations were showing zeta potential varying from +15 to +25 for both SF and PF batches which indicated a sign of high stability of prepared SLNs. After successfully optimizing the SLNs formulation and achieving particle within the administration range for drug delivery to brain, we set out to characterize the prepared SLNs thoroughly for their stability. The stability of SLNs during synthesis and storage is critical aspects, as particles can get aggregated and grow, if they are not stable. Zeta potential of the particles can be used as one of the measures for the stability of SLNs. These formulations were considered for further studies.

Table 4. Particle size and PDI of Stearic acid formulations (SF Batches).

\begin{tabular}{|c|c|c|c|}
\hline Sr. No. & Formulation & Particle Size (nm) & Polydispersity Index (PDI) \\
\hline 1. & SF1 & 124.4 & 0.262 \\
\hline 2. & SF2 & 179.3 & 0.261 \\
\hline 3. & SF3 & 281.9 & 0.278 \\
\hline 4. & SF4 & 298.1 & 0.317 \\
\hline 5. & SF5 & 298.0 & 0.330 \\
\hline 6. & SF6 & 143.8 & 0.256 \\
\hline 7. & SF7 & 269.8 & 0.650 \\
\hline 8. & SF8 & 331.4 & 0.397 \\
\hline
\end{tabular}

Table 5. Particle size and PDI of Palmitic acid formulations (PF Batches).

\begin{tabular}{|c|c|c|c|}
\hline Sr. No. & Formulation & Particle Size (nm) & Polydispersity Index (PDI) \\
\hline 1. & PF1 & 137.1 & 0.269 \\
\hline 2. & PF2 & 189.7 & 0.240 \\
\hline 3. & PF3 & 231.7 & 0.217 \\
\hline 4. & PF4 & 246.3 & 0.339 \\
\hline 5. & PF5 & 284.5 & 0.219 \\
\hline 6. & PF6 & 154.1 & 0.241 \\
\hline 7. & PF7 & 285.8 & 0.362 \\
\hline 8. & PF8 & 318.1 & 0.415 \\
\hline
\end{tabular}

Table 6. Zeta potential of selected formulations from SF and PF Batches.

\begin{tabular}{|c|c|c|}
\hline Sr. No. & Formulation & Zeta Potential (mV) \\
\hline 1. & SF1 & +15.74 \\
\hline 2. & SF2 & +25.89 \\
\hline 3. & SF6 & +25.44 \\
\hline 4. & PF1 & +21.53 \\
\hline 5. & PF2 & +19.69 \\
\hline 6. & PF6 & +15.11 \\
\hline
\end{tabular}

\subsection{Drug Entrapment Efficiency}

The entrapment efficiency of prepared SLNs was determined by UV-Visible spectrophotometer. At $291.2 \mathrm{~nm} \lambda_{\max }$ absorbance was determined and after calculations, the entrapment efficiency was computed which is given in the table below. Lipids show positive influence on entrapment efficiency; this result can probably be attributed to the high affinity of the lipophilic drug for the lipid material as well as the presence of span 60 . The selected formulations were able to entrap $\sim 90 \%$ or more drug. The results are tabulated below (Table 7). 
Table 7. Entrapment Efficiency of selected formulations.

\begin{tabular}{|c|c|c|}
\hline Sr. No. & Formulation & Entrapment Efficiency (\%) \\
\hline 1. & SF1 & 90.79 \\
\hline 2. & SF2 & 88.57 \\
\hline 3. & SF6 & 90.29 \\
\hline 4. & PF1 & 92.04 \\
\hline 5. & PF2 & 89.62 \\
\hline 6. & PF6 & 91.16 \\
\hline
\end{tabular}

\subsection{In Vitro Drug Release Study}

Cumulative amount of drug release was plotted against time to obtain release profile. It was observed that there was an initial rapid release followed by slower release rate. This initial burst rate may be due to the desorption of drug associated with the surface of nanoparticles and the slower release in the later stage was attributed to the fact that solubilized drug can only be released slowly from the lipid matrices due to dissolution and diffusion. All the 6 formulations were able to release the drug at a sustained release up to 24 hours in phosphate buffer $\mathrm{pH}$ 6.8. The release pattern observed in Stearic acid and Palmitic acid formulations is shown in Figs. (3 and 4) respectively and dissolution data is tabulated below (Table 8).

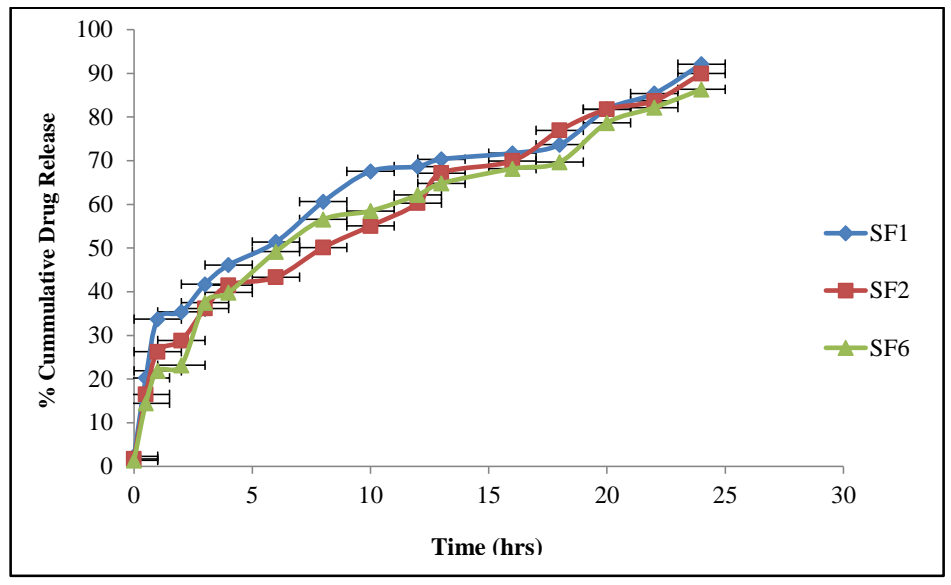

Fig. (3). \% Cumulative drug release of Levosulpiride loaded SLNs from Stearic acid batch (selected formulations). The error bars indicate the standard deviation of three tests.

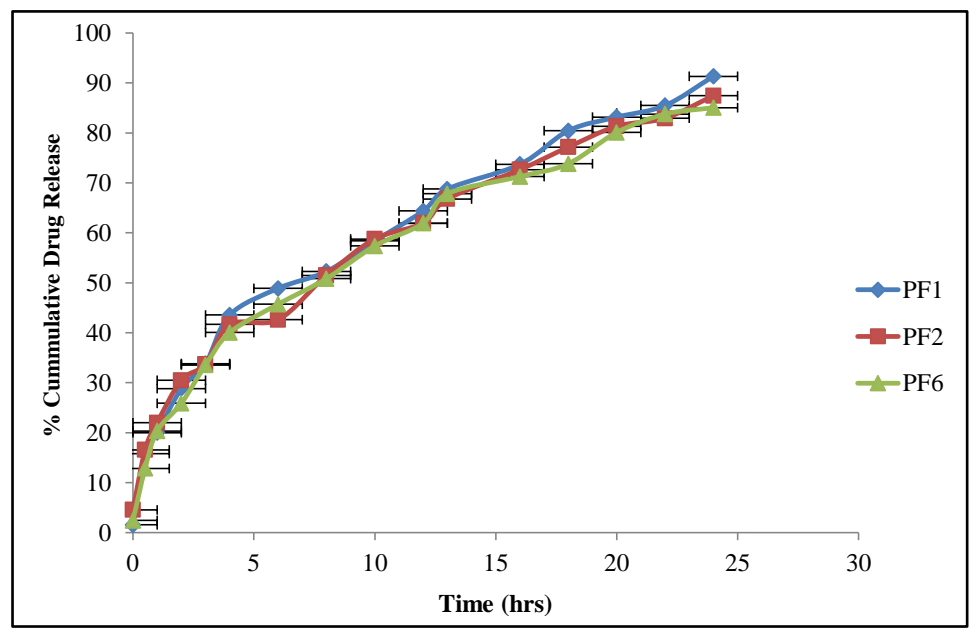

Fig. (4). \% Cumulative drug release of Levosulpiride loaded SLNs from Palmitic acid batch (selected formulations). The error bars indicate the standard deviation of 3 tests. 
Table 8. \% cumulative drug release of Levosulpiride loaded SLNs.

\begin{tabular}{|c|c|c|c|c|c|c|}
\hline \multirow{2}{*}{ Time } & \multicolumn{7}{|c|}{ \% Cummulative Drug Released \pm SD (n=3) } \\
\cline { 2 - 7 } & SF1 & SF2 & SF6 & PF1 & PF2 & PF6 \\
\hline $0 \mathrm{~min}$ & $2.33 \pm 0.35$ & $1.72 \pm 0.20$ & $1.38 \pm 0.08$ & $1.55 \pm 0.07$ & $4.55 \pm 0.28$ & $2.44 \pm 0.67$ \\
\hline $30 \mathrm{~min}$ & $20.27 \pm 0.34$ & $16.49 \pm 0.13$ & $14.46 \pm 1.29$ & $15.83 \pm 0.13$ & $16.55 \pm 0.15$ & $12.83 \pm 0.13$ \\
\hline $1 \mathrm{hr}$ & $33.71 \pm 0.47$ & $26.27 \pm 0.20$ & $21.88 \pm 0.28$ & $19.99 \pm 0.23$ & $21.99 \pm 0.13$ & $20.33 \pm 0.75$ \\
\hline $2 \mathrm{hr}$ & $35.38 \pm 0.79$ & $28.83 \pm 0.20$ & $23.16 \pm 0.13$ & $28.83 \pm 0.26$ & $30.49 \pm 0.23$ & $25.88 \pm 0.08$ \\
\hline $3 \mathrm{hr}$ & $41.72 \pm 0.20$ & $36.16 \pm 0.23$ & $37.49 \pm 0.13$ & $33.83 \pm 0.26$ & $33.72 \pm 0.20$ & $33.55 \pm 0.20$ \\
\hline $4 \mathrm{hr}$ & $46.11 \pm 0.54$ & $41.49 \pm 0.36$ & $39.83 \pm 0.13$ & $43.55 \pm 0.20$ & $41.66 \pm 0.23$ & $40.05 \pm 0.54$ \\
\hline $6 \mathrm{hr}$ & $51.38 \pm 0.47$ & $43.33 \pm 0.13$ & $49.16 \pm 0.13$ & $48.88 \pm 0.90$ & $42.61 \pm 0.28$ & $45.71 \pm 0.47$ \\
\hline $8 \mathrm{hr}$ & $60.61 \pm 0.43$ & $50.10 \pm 0.34$ & $56.55 \pm 0.20$ & $52.27 \pm 1.02$ & $51.49 \pm 0.13$ & $50.83 \pm 0.13$ \\
\hline $10 \mathrm{hr}$ & $67.55 \pm 0.34$ & $55.05 \pm 0.31$ & $58.49 \pm 0.27$ & $58.38 \pm 0.82$ & $58.77 \pm 0.16$ & $57.38 \pm 2.39$ \\
\hline $12 \mathrm{hr}$ & $68.66 \pm 0.36$ & $60.27 \pm 0.16$ & $62.16 \pm 0.13$ & $64.38 \pm 1.80$ & $61.94 \pm 0.90$ & $61.94 \pm 1.01$ \\
\hline $14 \mathrm{hr}$ & $70.33 \pm 0.49$ & $67.16 \pm 0.36$ & $64.82 \pm 0.23$ & $68.77 \pm 1.02$ & $66.77 \pm 1.14$ & $67.83 \pm 1.29$ \\
\hline $16 \mathrm{hr}$ & $71.72 \pm 0.28$ & $69.94 \pm 0.28$ & $68.16 \pm 0.13$ & $73.71 \pm 0.75$ & $72.66 \pm 1.20$ & $71.27 \pm 0.88$ \\
\hline $18 \mathrm{hr}$ & $73.66 \pm 0.27$ & $76.94 \pm 0.15$ & $69.66 \pm 0.13$ & $80.44 \pm 1.41$ & $77.16 \pm 3.08$ & $73.83 \pm 0.35$ \\
\hline $20 \mathrm{hr}$ & $81.77 \pm 0.41$ & $81.77 \pm 0.39$ & $78.66 \pm 0.23$ & $83.16 \pm 1.77$ & $81.33 \pm 0.81$ & $80.10 \pm 0.034$ \\
\hline $22 \mathrm{hr}$ & $85.38 \pm 0.69$ & $83.71 \pm 0.47$ & $82.16 \pm 0.36$ & $85.49 \pm 1.53$ & $82.94 \pm 0.34$ & $83.77 \pm 0.56$ \\
\hline $24 \mathrm{hr}$ & $92.11 \pm 0.43$ & $89.94 \pm 0.28$ & $86.33 \pm 0.35$ & $91.33 \pm 0.13$ & $87.44 \pm 0.20$ & $85.05 \pm 0.34$ \\
\hline
\end{tabular}

\subsection{Drug Release Kinetics}

The prepared SLNs were subjected to the drug release kinetics and release mechanism. The formulations were studied by fitting the drug release time profile with the various equations such as Zero order, First order, Higuchi and Korsmeyer pappas. All the formulations (SF1, SF2, SF6, PF1, PF2 and PF6) were analyzed for the drug release mechanism. The data revealed a better fit to the Higuchi diffusion model with $\mathrm{n}$ value less than 0.43 i.e. Fickian diffusion for SF batch formulations and the drug release was dependent on time. On the other hand, Higuchi anomalous diffusion (non-Fickian) was observed for PF batch formulations owing to $n$ value $>0.43<1$ which could be attributed to the fact that the diffusion refers to combination of both diffusion and erosion controlled rate release [25].

The results are presented in Tables (9 and 10) and Figs. (5 and 6$)$ below:

Table 9. Drug release kinetics for Stearic acid formulations.

\begin{tabular}{|c|c|c|c|c|c|c|c|c|}
\hline \multirow{2}{*}{ Formulations } & \multicolumn{2}{|c|}{ Zero Order } & \multicolumn{2}{|c|}{ First Order } & \multicolumn{2}{|c|}{ Higuchi } & \multicolumn{2}{|c|}{ Korsmeyer Peppas } \\
\hline & $\mathbf{K}\left(\mathbf{h}^{-1}\right)$ & $\mathbf{R}^{2}$ & $K_{1}\left(h^{-1}\right)$ & $\mathbf{R}^{2}$ & $\mathbf{K}_{\mathrm{H}}\left(\mathrm{h}^{-1 / 2}\right)$ & $\mathbf{R}^{2}$ & $\mathbf{N}$ & $\mathbf{R}^{2}$ \\
\hline SF1 & 3.003 & 0.906 & 0.038 & 0.963 & 16.71 & 0.984 & 0.256 & 0.968 \\
\hline SF2 & 3.062 & 0.937 & 0.034 & 0.966 & 16.82 & 0.991 & 0.321 & 0.975 \\
\hline$\overline{\text { SF6 }}$ & 2.991 & 0.902 & 0.030 & 0.976 & 16.72 & 0.988 & 0.405 & 0.973 \\
\hline
\end{tabular}

Table 10. Drug release kinetics for Palmitic acid formulations.

\begin{tabular}{|c|c|c|c|c|c|c|c|c|}
\hline \multirow{2}{*}{ Formulations } & \multicolumn{2}{|c|}{ Zero Order } & \multicolumn{2}{|c|}{ First Order } & \multicolumn{2}{|c|}{ Higuchi } & \multicolumn{2}{|c|}{ Korsmeyer Peppas } \\
\hline & $K\left(h^{-1}\right)$ & $\mathbf{R}^{2}$ & $K_{1}\left(h^{-1}\right)$ & $\mathbf{R}^{2}$ & $K_{H}\left(h^{-1 / 2}\right)$ & $\mathbf{R}^{2}$ & $\mathbf{N}$ & $\mathbf{R}^{2}$ \\
\hline PF1 & 3.223 & 0.928 & 3.223 & 0.928 & 17.84 & 0.996 & 0.464 & 0.982 \\
\hline PF2 & 3.046 & 0.937 & 3.046 & 0.937 & 16.77 & 0.996 & 0.496 & 0.989 \\
\hline PF6 & 3.109 & 0.929 & 3.109 & 0.929 & 17.21 & 0.997 & 0.464 & 0.984 \\
\hline
\end{tabular}

\subsection{FTIR Studies}

The compatibility studies were conducted by using FTIR spectral and DSC thermogram studies. The results obtained for the FTIR spectra of Levosulpiride and lipids (Stearic acid/Plmitic acid) individually and the final formulation suggested that the characteristic bands observed in Levosulpiride pure samples were mostly identical with the peaks in the final formulation of Levosulpiride and lipids adhering within their ranges without changes in the functionalities indicating its compatibility Fig. (7). 

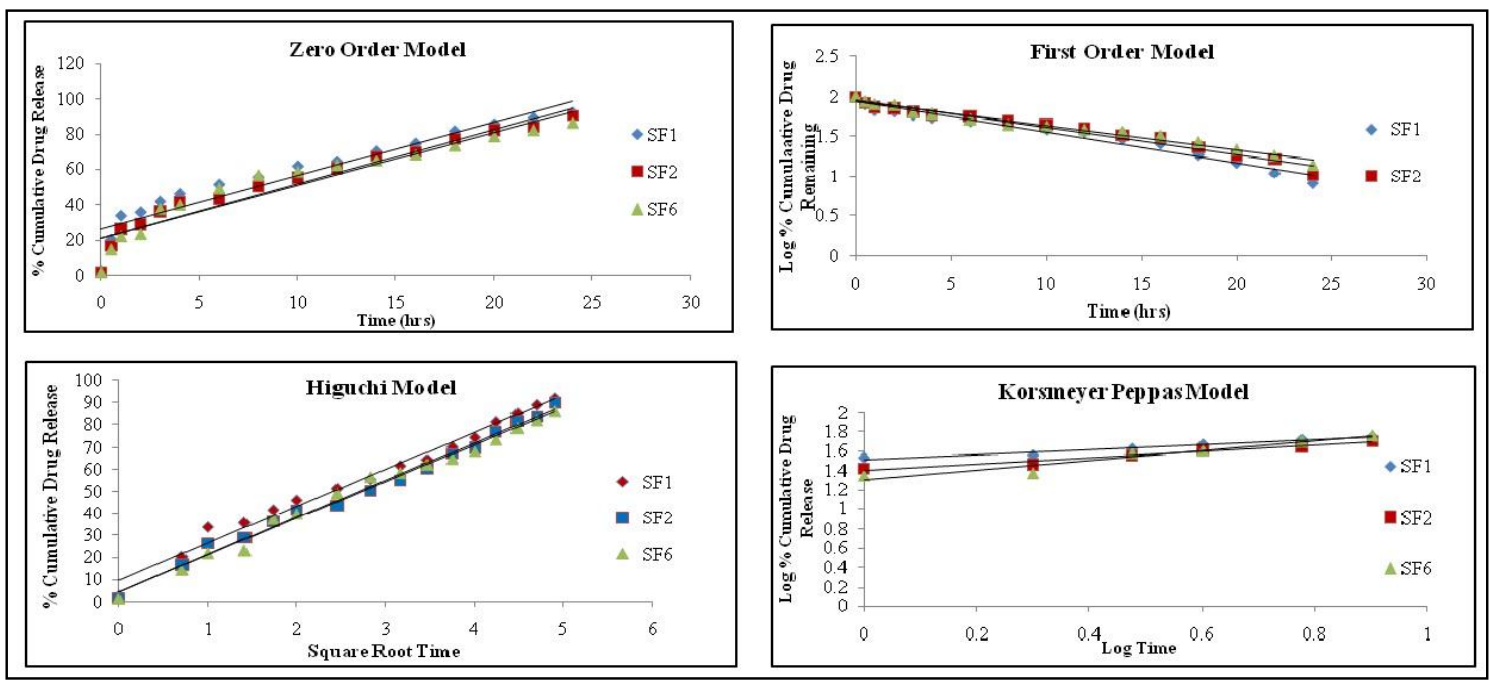

Fig. (5). Kinetics of drug release for Stearic acid formulations- a). Zero order model; b). First order model; c). Higuchi model; d). Korsmeyer-Peppas model.

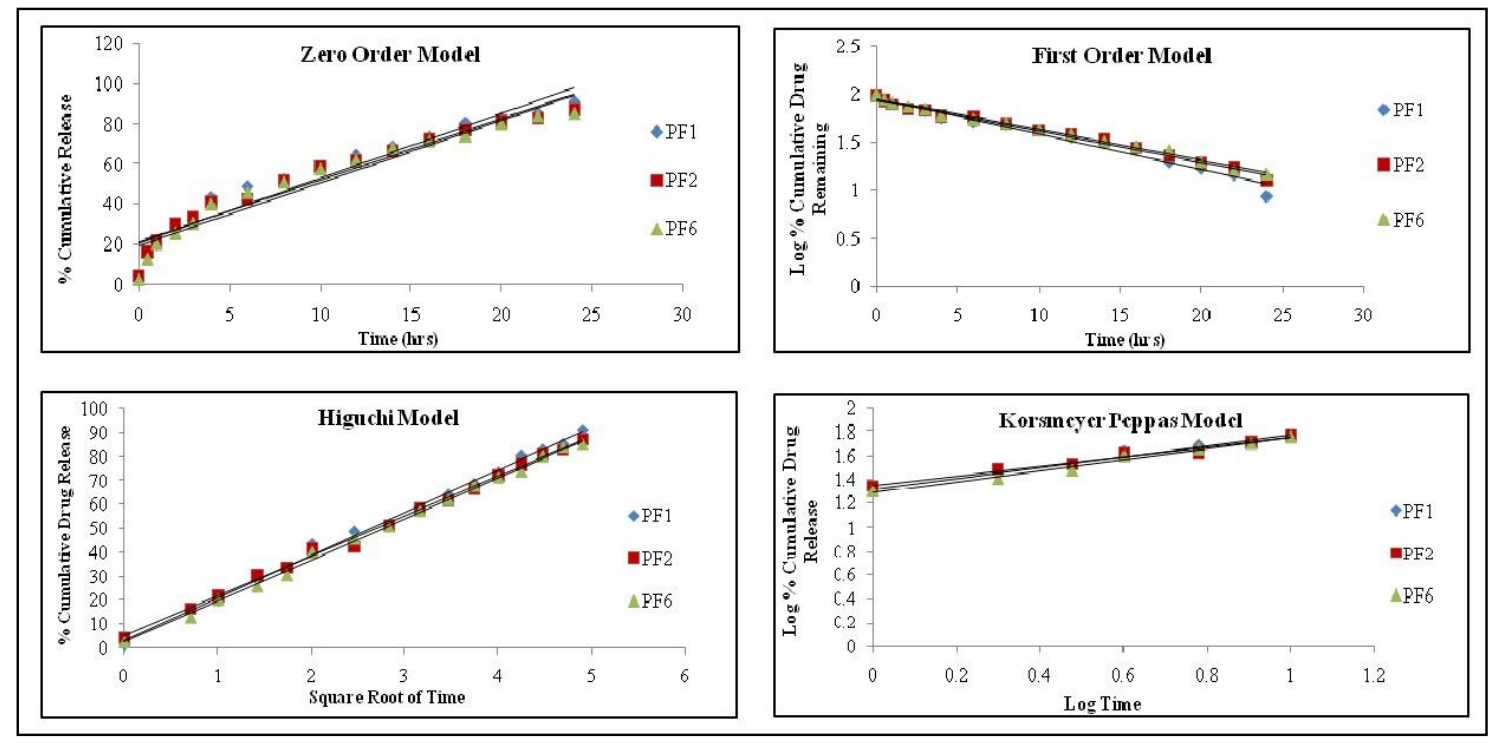

Fig. (6). Kinetics of drug release for Palmitic acid formulations- a). Zero order model; b). First order model; c). Higuchi model; d). Korsmeyer-Peppas model.

\subsection{DSC Studies}

In DSC themograms (Fig. 8) it is clear that the drug was solubilized on the lipid, because there are no melting events of Levosulpiride on the SLNs formulations. Furthermore, a small decrease on the onset and on the melting temperature of the lipid when it is formulated with drug was observed. The reduction was higher when the amount of drug increased, which is more evident by the values of peak width.

\subsection{Transmission Electron Microscopy (TEM)}

TEM images for formulations SF1 and PF1 (Figs. (9 and 10) respectively) were captured with Hitachi H7500. The images indicated that the Levosulpiride loaded solid lipid nanoparticles were in nanometric range (below $250 \mathrm{~nm}$ ) with rough surfaced irregular spherical shape. 


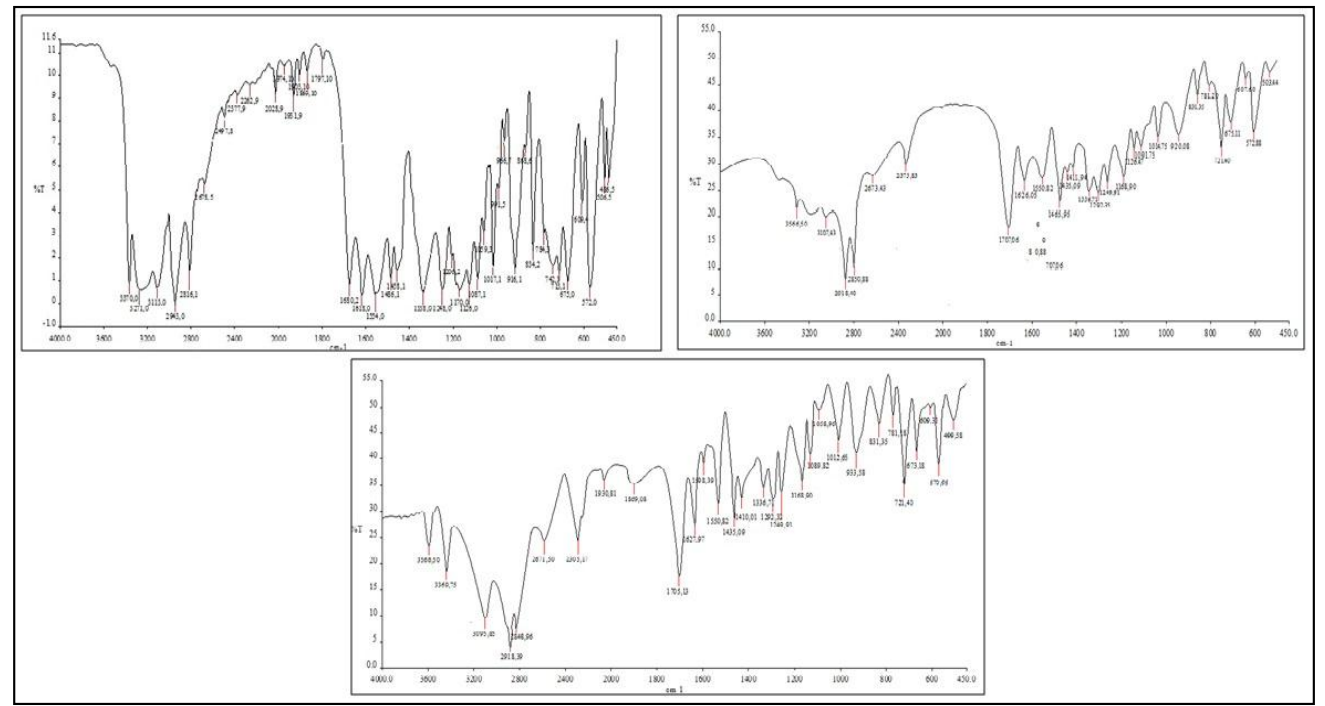

Fig. (7). FTIR spectra of- a). Levosulpiride; b). Formulation SF1; c). Formulation PF1.

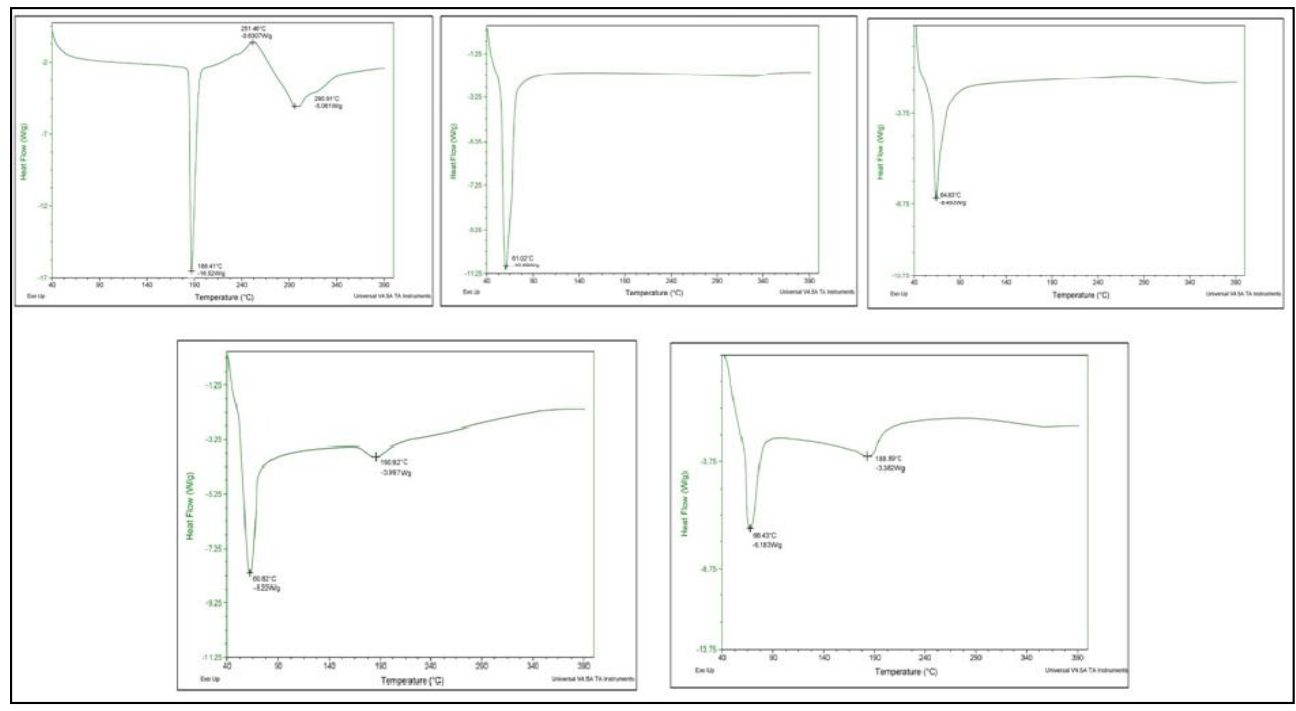

Fig. (8). DSC Thermograms of- a). Levosulpiride (Pure Drug); b). Stearic acid; c). Palmitic acid; d). Formulation SF1; e). Formulation PF1.

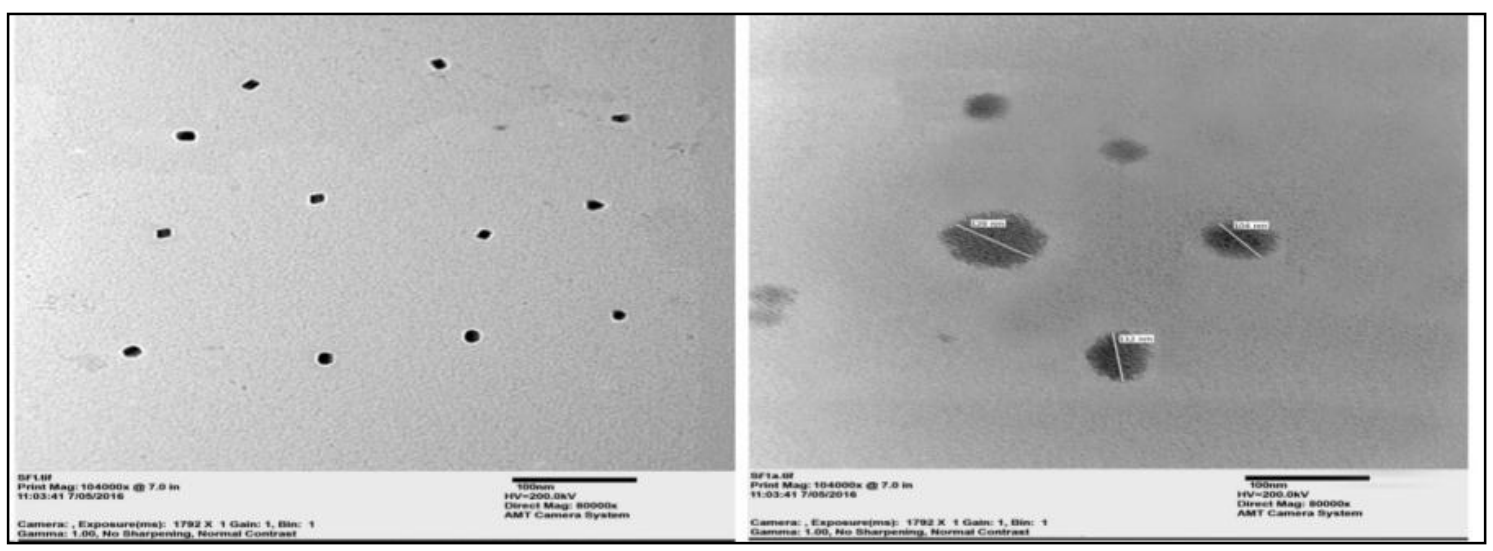

Fig. (9). TEM images of formulation SF1. 


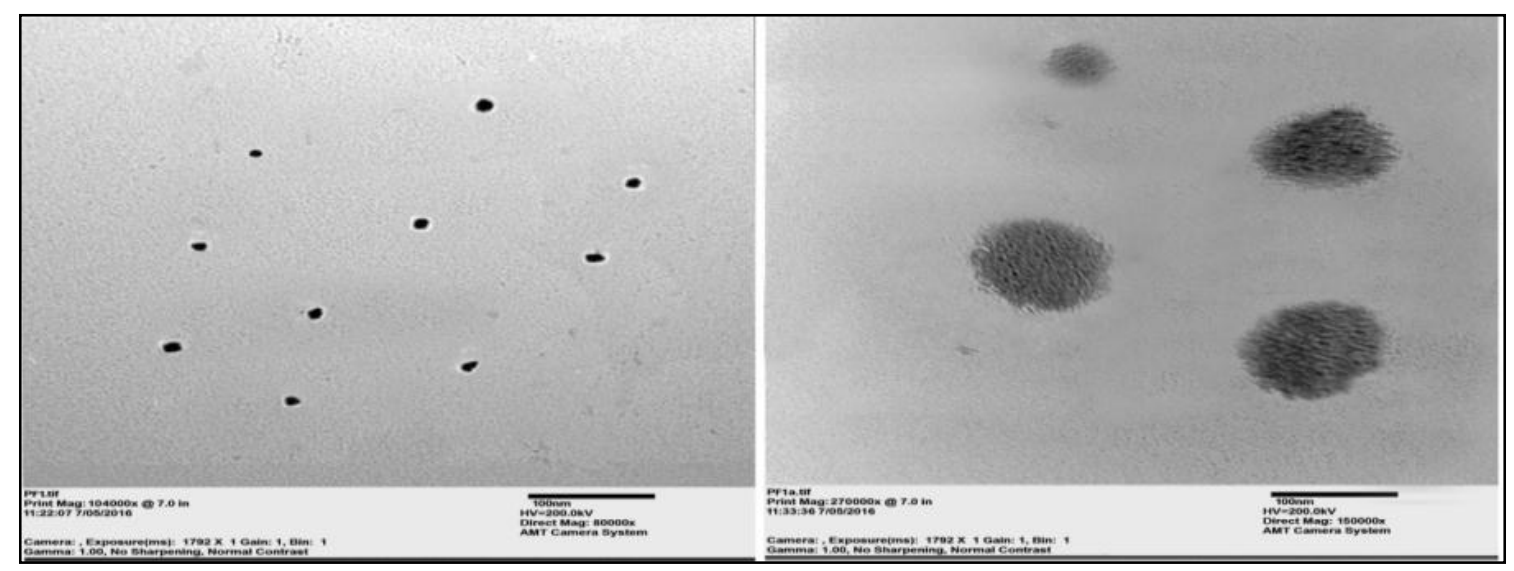

Fig. (10). TEM images of formulation PF1.

\section{CONCLUSION}

A total of 16 formulations were prepared (8 for each lipid i.e. Stearic acid and Palmitic acid; SF1-SF8 and PF1-PF8 respectively) using a $2^{3}$ full factorial design. Optimized formulations were characterized for particle size analysis, zeta potential, drug entrapment efficiency and in vitro drug release study. The particle size of SF1, SF2, SF6, PF1, PF2 and PF6 was measured to be $124.4 \mathrm{~nm}, 179.3 \mathrm{~nm}, 143.8 \mathrm{~nm}, 137.1,189.7$ and $154.1 \mathrm{~nm}$ respectively using Zetasizer, which was in desired range. SLN formulations were found to be stable with zeta potential between +15 to $+30 \mathrm{mV}$ and drug entrapment efficiency was reported to be approximately $90 \%$ for selected formulations. From in vitro drug release study, the \% cumulative drug release after $24 \mathrm{hrs}$ from SF1, SF2, SF6, PF1, PF2 and PF6 was recorded to be $92.11 \pm 43 \%, 89.94 \pm 0.28 \%, 86.33 \pm 0.35 \%, 91.33 \pm 13 \%, 87.44 \pm 0.20 \%$ and $85.05 \pm 0.34 \%$ respectively. Mechanism of drug release was found to follow Higuchi diffusion model; Fickian diffusion for SF batch formulations and non-Fickian diffusion for PF batch formulations. The highest cumulative \% drug releasing formulation from each batch (i.e. SF 1 and PF1) was chosen for further evaluations. A decrease in the enthalpy and onset temperature for the melting point of lipids (stearic acid and palmitic acid) in the DSC thermograms confirmed the reduction in the particle size as well as conversion of drug from crystalline to amorphous nature. From FTIR analysis, no physical as well as chemical changes were observed. Morphological studies using TEM images showed spherical to oval particles with well defined periphery. The SLNs appeared to be less dense in the core with a well defined shell. The successful incorporation of Levosulpiride into SLNs opens a wide scope of the study of the delivery system with respect to sustained and targeted drug delivery. However the in vivo studies are yet to be carried out to confirm the potential of formulated SLNs.

\section{ETHICS APPROVAL AND CONSENT TO PARTICIPATE}

Not applicable.

\section{HUMAN AND ANIMAL RIGHTS}

No Animals/Humans were used for studies that are base of this research.

\section{CONSENT FOR PUBLICATION}

Not applicable.

\section{CONFLICT OF INTEREST}

The authors declare no conflict of interest, financial or otherwise.

\section{ACKNOWLEDGEMENTS}

Declared none.

\section{REFERENCES}


[http://dx.doi.org/10.1016/S1474-4422(12)70313-7] [PMID: 23237899]

[2] Re F, Gregori M, Masserini M. Nanotechnology for neurodegenerative disorders. Maturitas 2012; 73(1): $45-51$. [http://dx.doi.org/10.1016/j.maturitas.2011.12.015] [PMID: 22261367]

[3] Youns M, Hoheisel JD, Efferth T. Therapeutic and diagnostic applications of nanoparticles. Curr Drug Targets 2011; 12(3): 357-65. [http://dx.doi.org/10.2174/138945011794815257] [PMID: 20955146]

[4] Uchegbu IF. Pharmaceutical nanotechnology: polymeric vesicles for drug and gene delivery. Expert Opin Drug Deliv 2006; 3(5): 629-40. [http://dx.doi.org/10.1517/17425247.3.5.629] [PMID: 16948558]

[5] Farokhzad OC. Nanotechnology for drug delivery: The perfect partnership. Expert Opin Drug Deliv 2008; 5(9): 927-9. [http://dx.doi.org/10.1517/17425247.5.9.927] [PMID: 18754745]

[6] Sun Y, Kang C, Wang M, Zhu J, Jin L, Cheng X. Nanosized camptothecin conjugates for single and combined drug delivery. Eur J BioMed Res 2016; 2: 8-16. [http://dx.doi.org/10.18088/ejbmr.2.1.2016.pp8-14]

[7] Müller RH, Mäder K, Gohla S. Solid lipid nanoparticles (SLN) for controlled drug delivery - a review of the state of the art. Eur J Pharm Biopharm 2000; 50(1): 161-77. [http://dx.doi.org/10.1016/S0939-6411(00)00087-4] [PMID: 10840199]

[8] Mehnert W, Mäder K. Solid lipid nanoparticles: production, characterization and applications. Adv Drug Deliv Rev 2001; 47(2-3): 165-96. [http://dx.doi.org/10.1016/S0169-409X(01)00105-3] [PMID: 11311991]

[9] Severino P, Andreani T, Macedo AS, Fangueiro JF, Santana MH, Silva AM, et al. Current state-of-art and new trends on lipid nanoparticles (SLN and NLC) for oral drug delivery. J Drug Del 2012; 2012: 750891.

[10] Martindale: The complete drug reference. Published by Pharmaceutical Press, Lambeta high street, Londan SEI 75M, UK. 2006.

[11] Song CW, Chun HJ, Kim CD, Ryu HS, Choe JG, Hyun JH. Effects of levosulpiride in patients with functional dyspepsia accompanied by delayed gastric emptying. Korean J Intern Med 1998; 13(1): 15-21. [http://dx.doi.org/10.3904/kjim.1998.13.1.15] [PMID: 9538626]

[12] Tonini M, Cipollina L, Poluzzi E, Crema F, Corazza GR, De Ponti F. Review article: clinical implications of enteric and central D2 receptor blockade by antidopaminergic gastrointestinal prokinetics. Aliment Pharmacol Ther 2004; 19(4): 379-90. [http://dx.doi.org/10.1111/j.1365-2036.2004.01867.x] [PMID: 14871277]

[13] Corazza GR, Tonni M. Levosulpiride for Dyspepsia and Emesis: A review of its Pharmacology, Efficacy and Tolerability. Clin Drug Investig 2000; 19: 151-62. [http://dx.doi.org/10.2165/00044011-200019020-00008]

[14] Pharmacokinetics. Pantocid.com. Available at: http://pantocid.com/pharmacokinetics.html

[15] Yoganand BD, Jigar AP, Moreshwar PM, Sanjay DS. UV spectrophotometric method for simultaneous estimation of rabeprazole sodium and levosulpiride in bulk and tablet dosage form. Pharma Chem 2013; 5: 163-8.

[16] Mehnert W, Mäder K. Solid lipid nanoparticles: Production, characterization and applications. Adv Drug Deliv Rev 2001; 47(2-3): 165-96. [http://dx.doi.org/10.1016/S0169-409X(01)00105-3] [PMID: 11311991]

[17] Kushwaha AK, Vuddanda PR, Karunanidhi P, Singh SK, Singh S. Development and Evaluation of Solid Lipid Nanoparticles of Raloxifene Hydrochloride for Enhanced Bioavailability. BioMed Res Int 2013; $2013: 584549$. [http://dx.doi.org/10.1155/2013/584549]

[18] Kim BD, Na K, Choi HK. Preparation and characterization of solid lipid nanoparticles (SLN) made of cacao butter and curdlan. Eur J Pharm Sci 2005; 24(2-3): 199-205. [http://dx.doi.org/10.1016/j.ejps.2004.10.008] [PMID: 15661491]

[19] Ji P, Yu T, Liu Y, et al. Naringenin-loaded solid lipid nanoparticles: preparation, controlled delivery, cellular uptake, and pulmonary pharmacokinetics. Drug Des Devel Ther 2016; 10: 911-25. [PMID: 27041995]

[20] Malewar N, Avachat M, Pokharkar V, Kulkarni S. Controlled release of ropinirole hydrochloride from a multiple barrier layer tablet dosage form: effect of polymer type on pharmacokinetics and IVIVC. AAPS PharmSciTech 2013; 14(3): 1178-89. [http://dx.doi.org/10.1208/s12249-013-0009-3] [PMID: 23897037]

[21] Costa P, Sousa Lobo JM. Modeling and comparison of dissolution profiles. Eur J Pharm Sci 2001; 13(2): $123-33$. [http://dx.doi.org/10.1016/S0928-0987(01)00095-1] [PMID: 11297896]

[22] Dash S, Murthy PN, Nath L, Chowdhury P. Kinetic modeling on drug release from controlled drug delivery systems. Acta Pol Pharm 2010; 67(3): 217-23. [PMID: 20524422]

[23] Nazir I, Abbas J, Asad M, Bashir S, Rasul A, Ahmad N. Formulation and in vitro Evaluation of Orodispersible tablet of Levosulpiride. J Pharm Cosm Sci 2013; 1: 53-6.

[24] Kumar R, Singh S, Kamal SS, Kaur D, Singh M, Katual MK. Development and Validation of Spectrophotometric Method for Estimation of Levosulpiride in Bulk and Tablet Dosage Form. Euras J Anal Chem 2017; 12: 265-73. 
[25] Ritger PL, Peppas NA. A simple equation for description of solute release I. Fickian and non-fickian release from nonswellable devices in the form of slabs, spheres, cylinders or discs. J Control Release 1987; 5: 23-36.

[http://dx.doi.org/10.1016/0168-3659(87)90034-4]

\section{(C) 2017 Kumar et al.}

This is an open access article distributed under the terms of the Creative Commons Attribution 4.0 International Public License (CC-BY 4.0), a copy of which is available at: https://creativecommons.org/licenses/by/4.0/legalcode. This license permits unrestricted use, distribution, and reproduction in any medium, provided the original author and source are credited. 